7-14 years). This delay is explained by the fact that none of the patients presented typical symptoms of DM1 at the time of the diagnosis of the cataract. Remarkably, apart from Christmas tree cataract, no other form of cataract was detected in the study group, as well as no other pathology regarding the anterior or posterior segment was recorded.

Notably, in previous studies, Christmas tree cataract has been detected in nearly all patients with DM1, and viceversa $16.7 \%$ of subjects with Christmas tree cataract have been diagnosed with DM1 [2].

In conclusion, earlier detection of Christmas tree cataract, which constitutes a common ophthalmologic finding in DM1 patients [3, 4], and thus, referral for neuromuscular assessment could possibly eliminate delays in diagnosis of the disease. Noteworthy, it seems that Christmas cataract may be the first manifestation of DM1 in a higher percentage of patients than posterior subcapsular cataract in DM2 patients. Extended multicenter studies may elucidate the exact incidence of the different cataract types in these patients.

\section{Compliance with ethical standards}

Conflict of interest The authors declare that they have no conflict of interest.

Informed consent Written informed consent was obtained from all patients and the study was approved by the institutional review board at the University of Patras.

\section{References}

1. Papadopoulos C, Kekou K, Xirou S, Kitsiou-Tzeli S, Kararizou E, Papadimas GK. Early onset posterior subscapular cataract in a series of myotonic dystrophy type 2 patients. Eye (Lond). 2018;32:622-625

2. Reiter C, Gramer E. Anticipation in patients with iridescent multicoloured posterior capsular lens opacities ("Christmas tree cataract"): the role in the diagnosis of myotonic dystrophy. Ophthalmologe. 2009;106:1116-20.

3. Bird TD. Myotonic dystrophy type 1. In: Adam MP, Ardinger HH, Pagon RA, et al., editors. GeneReview [Internet]. Seattle, WA: University of Washington; Seattle; 1999. p. 1993-2017.

4. Stival L, Bittar R, Lago A, Nassaralla J Jr. Christmas tree cataract. Rev Bras Oftalmol. 2015;74:309-11.

\title{
Hypothyroidism and non-infectious uveitis
}

\author{
Shorya Vardhan Azad ${ }^{1} \cdot$ Varun Gogia $^{1} \cdot$ Pradeep Venkatesh $^{1} \cdot$ Brijesh Takkar $^{1}$
}

Received: 7 February 2018 / Accepted: 12 February 2018 / Published online: 24 July 2018

(c) The Royal College of Ophthalmologists 2018

Understanding the non-specific symptoms of uveitis and its corroboration with systemic findings may give insight into its pathophysiology and may in turn help in its management. Association of thyroid disorders with uveitis is well known; however, emphasis has not been made in most of the past studies regarding its prevalence and spectrum of presentation $[1,2]$.

We performed a prospective analysis of patients presenting at our uvea clinic at a tertiary eye care center in Northern India and evaluated the patterns of uveitis in our

Pradeep Venkatesh

venkyprao@yahoo.com

1 Dr. Rajendra Prasad Centre for Ophthalmic Sciences, AIIMS, New Delhi, India population. As a part of study we also analyzed the prevalence of associated systemic diseases and systemic symptoms. We observed that $24.5 \%$ of patients of uveitis had underlying systemic disease, where past or present evidence of tuberculosis was most common followed by seronegative spondyloarthropathy and sarcoidosis with overall prevalence of $6.8 \%, 4.1 \%$, and $2.5 \%$, respectively. Prevalence of hypothyroidism in these patients was $1.5 \%$ amongst (12 patients out of 800 ) all patients and 6.1\% among patients with known systemic illness. There were 10 females and 2 males with median age of 37 years (Table 1). Spectrum of involvement was varied, with intermediate uveitis (IU) being the most common presentation. All patients had confirmed hypothyroidism and were on thyroid replacement therapy. None of them suffered from hyperthyroidism. Thyroid functions tests and anti-thyroid 
Table 1 Demographic features, laterality and anatomical involvement in patients with thyroid dysfunction and uveitis

\begin{tabular}{|c|c|c|c|c|}
\hline $\begin{array}{l}\text { Age of } \\
\text { patient } \\
\text { (years) }\end{array}$ & Gender & $\begin{array}{l}\text { Laterality of } \\
\text { the disease }\end{array}$ & $\begin{array}{l}\text { Anatomical } \\
\text { classification of } \\
\text { uveitis }\end{array}$ & $\begin{array}{l}\text { Systemic } \\
\text { symptoms }\end{array}$ \\
\hline 20 & Male & Unilateral & Posterior & Joint pains \\
\hline 40 & Female & Bilateral & Intermediate & None \\
\hline 33 & Female & Unilateral & Intermediate & None \\
\hline 32 & Female & Bilateral & Anterior & None \\
\hline 35 & Female & Bilateral & Anterior & None \\
\hline 36 & Male & Unilateral & Intermediate & None \\
\hline 38 & Female & Bilateral & Panuveitis & None \\
\hline 52 & Female & Bilateral & Anterior & None \\
\hline 40 & Female & Unilateral & Intermediate & None \\
\hline 42 & Female & Bilateral & Intermediate & None \\
\hline 42 & Female & Unilateral & Intermediate & Joint pains \\
\hline 33 & Female & Unilateral & Anterior & None \\
\hline
\end{tabular}

antibodies were not ordered at the time of presentation as all patients were already on treatment.

Numerous studies have described systemic associations of uveitis, however, only a few studies have reported such an association between thyroid dysfunction and uveitis [3, 4]. Also, none of them have assessed the prevalence and type of uveitis. A previous study that investigated the relationship between thyroid dysfunction and uveitis, concluded that hypothyroidism was a more frequent association [1]. Our analysis echoed similar results with none of the patients having hyperthyroidism. However, aforementioned study tested thyroxine levels in all patients with or without a specific etiological diagnosis whereas our study included only patients with an established diagnosis of hypothyroidism by an endocrinologist. When compared to prevalence of hypothyroidism in community, nearly $10 \%$ of normal population also have subclinical hypothyroidism [5]. Hence, the data described here might be an underestimation of associated hypothyroidism because we did not order thyroid function tests in other idiopathic uveitis which is a major limitation.

Another important component of our analysis was the anatomical category of uveitis. This revealed IU as being the most common presentation (50\%). Similar study evaluating systemic associations in IU, showed an overall prevalence of thyroid dysfunction at $6.02 \%$ among all patients of IU and $19.23 \%$ amongst patients with known systemic illness [2]. In their study 3 patients had hypothyroidism. Although we cannot decipher a direct causal relationship of thyroid abnormalities and uveitis, concurrent systemic disease may play a role in predisposition for the same.

In conclusion, we highlight surprisingly frequent prevalence of thyroid dysfunction in patients with noninfectious uveitis and its varied presentations. Routine evaluation of thyroid function and related antibodies in cases of idiopathic uveitis may likely seem justified and may reveal a higher association.

\section{Compliance with ethical standards}

Conflict of interest The authors declare that they have no conflict of interest.

\section{References}

1. Cantor LB, Weber JC, Schlaegel TF. Thyroid dysfunction and uveitis. Ann Ophthalmol. 1982;14:515-7.

2. Boskovich SA, Lowder CY, Meisler DM, Gutman FA. Systemic diseases associated with intermediate uveitis. Cleve Clin J Med. 1993;60:460-5.

3. Rathinam SR, Namperumalsamy P. Global variation and pattern changes in epidemiology of uveitis. Indian $\mathrm{J}$ Ophthalmol. 2007;55:173-83.

4. Das D, Bhattacharjee H, Bhattacharyya PK, Jain L, Panicker MJ, Das K, et al. Pattern of uveitis in North East India: a tertiary eye care center study. Indian J Ophthalmol. 2009;57:144-6.

5. Usha Menon V, Sundaram KR, Unnikrishnan AG, Jayakumar RV, Nair V, Kumar H. High prevalence of undetected thyroid disorders in an iodine sufficient adult south Indian population. J Indian Med Assoc. 2009;107:72-7. 